\title{
Technique
}

\section{A new disposable probe for recording intraluminal pressure and electric potentials in the human gastrointestinal tract}

SVEN DORPH, ADAM ØIGAARD, AND MICHAEL KRAGSHOLM From the Radiological Department, Rigshospitalet (University Hospital), Copenhagen, Denmark

Most of the present knowledge of gastrointestinal motility originates from the study of electrical activity and intraluminal pressure in laboratory animals. Although considerable physiological information has been gathered from such experiments, the clinical applications have so far been very limited and further investigation is warranted in order to establish the usefulness and limitations of gastrointestinal motility studies as a clinical routine (Connell, 1967).

Various probes have been described for intraluminal pressure and electric potential recording in the intact human gastrointestinal canal. Christensen, Schedl, and Clifton (1964), use a silver silverchloride KCL salt-bridge electrode for monopolar recording of the electric potentials. A small rubber balloon is used for the intraluminal pressure registration. There is no close contact between the electrode and the intestinal wall. Monges and Salducci (1970) use bipolar leads. The electrodes are mounted in a small rubber suction cup. A small balloon is used for pressure registration. Drewes (1971) has two platinum electrodes embedded in the edge of a funnel-shaped side hole which is held in position by suction. Intraluminal pressure is recorded through an open-ended catheter as well as a miniature balloon.

Although these and other devices have provided reliable and reproducible results, they all seem too complicated for more widespread use. Furthermore, the distress caused by introducing a large tube transorally militates against the production of normal motor activity by the gut (Quigley and Brody, 1952).

\section{Materials and Design}

In collaboration with Univel Inc, we have constructed a new probe which is relatively simple and

Received for publication 18 July 1972 available at a moderate price for disposable use. The probe has the outer proportions of an ordinary duodenal tube so that it can be introduced transnasally. For duodenal intubation a metal guide wire can be introduced via the pressure catheter when the tip of the probe is in the stomach.

The probe (Fig. 1) consists of an ordinary stomach tube size 18 french gauge, $118 \mathrm{~cm}$ long, containing an inner radioopaque polyethylene catheter (inner diameter $1.3 \mathrm{~mm}$, outer diameter $1.7 \mathrm{~mm}$ ) and a shielded cable with two 10-strand fine copper wires. The bipolar electrodes are formed from the distal end of the wires which have been wound around a

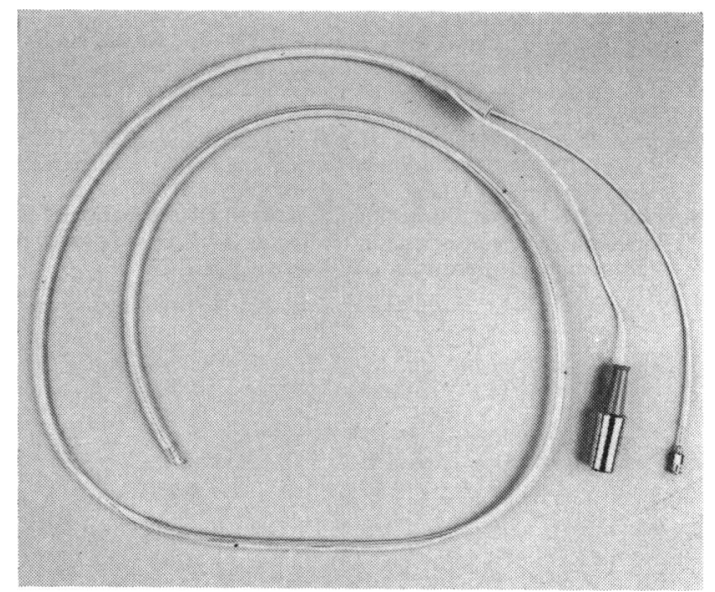

Fig. 1 Probe for intraluminal registration of electrical potentials and pressure variations.

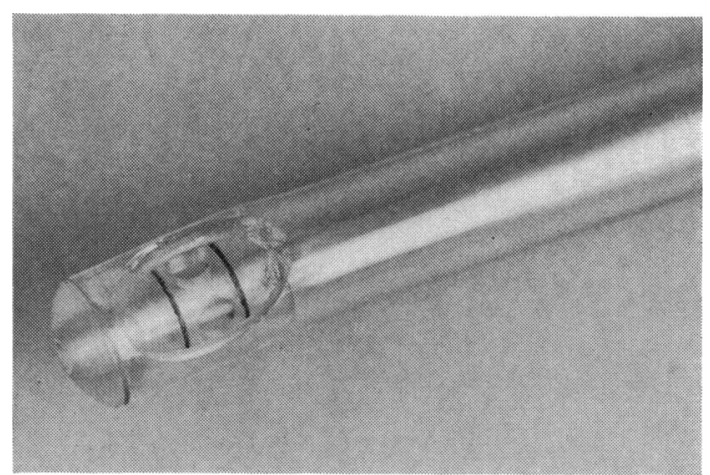

Fig. 2 Distal end of probe with exposed part of electrodes. Two holes for suction between electrodes. Pressure catheter opening at the tip of the probe. 
central core of acrylic plastic. The electrodes are exposed over $30^{\circ}$ of their circumference through an oval-shaped side hole close to the end of the outer catheter (Fig. 2). In order to improve electrical contact, suction can be applied to the holes between the electrodes. The interelectrode distance is $3 \mathrm{~mm}$ and the exposed area of each electrode is approximately $0.1 \times 3 \mathrm{~mm}$.

Potential and pressure curves are recorded on an Elema-Scönander multichannel mingograph with an EMT 12b preamplifier with differential input: input impedance, $50 \mathrm{M} \Omega / 800 \mathrm{pF}$; upper frequency limit $15-30 \mathrm{~Hz}$. The time constant is kept at $0.06 \mathrm{sec}$ for spike recording and $1.2 \mathrm{sec}$ for recording of slow waves. Pressure variations are transmitted to the mingograph through an Elema-Schönander EMT 460 transducer with an upper frequency limit of $15 \mathrm{~Hz}$.

The probe is now in daily use in our department, and the preliminary results have been very promising. As shown in Figs. 3 and 4, spike potentials are well defined and easy to measure. Correlation between spike potentials and pressure elevation is good.
Slow waves (Fig. 5) are less easily detected with this technique, since fluctuations in the baseline are liable to occur with a time constant of $1.2 \mathrm{sec}$, and accordingly the sensitivity must be kept on 500 $\mu \mathrm{V} / \mathrm{cm}$.

\section{Comment}

We feel that recording spike potentials alone will be most rewarding for quantitation of gastrointestinal motility in clinical practice.

Since the probe is introduced transnasally, it is possible to record over a longer period under more physiological conditions, and manipulations for duodenal intubation become less trying to the patient.

Since cables and electrodes are in one piece there is no risk of false potentials arising from galvanic action. In our experience, platinum electrodes are not superior to copper electrodes. From a theoretical point of view, copper is possibly an even more suitable electrode material than platinum or silver because the corrosion potentials of the copper

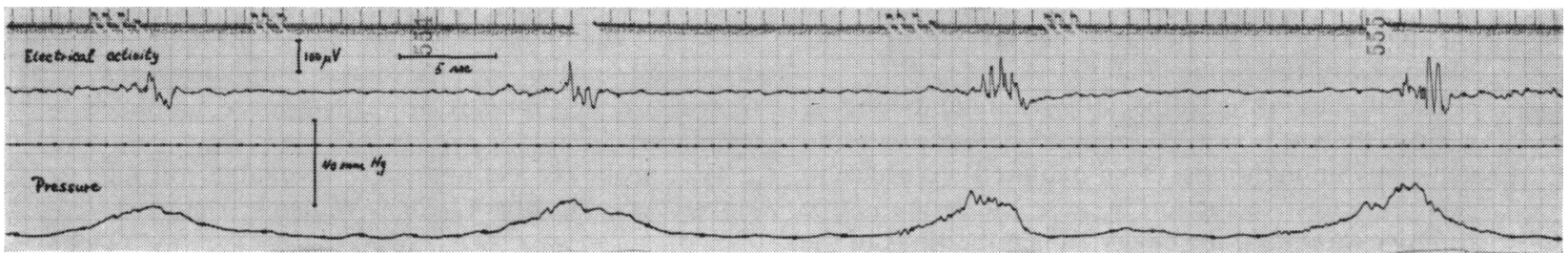

Fig. 3 Recording from antral part of the stomach. Electrical time constant 0.06 seconds. Spontaneous rhythmical bursts of fast spikes accompanied by pressure waves.

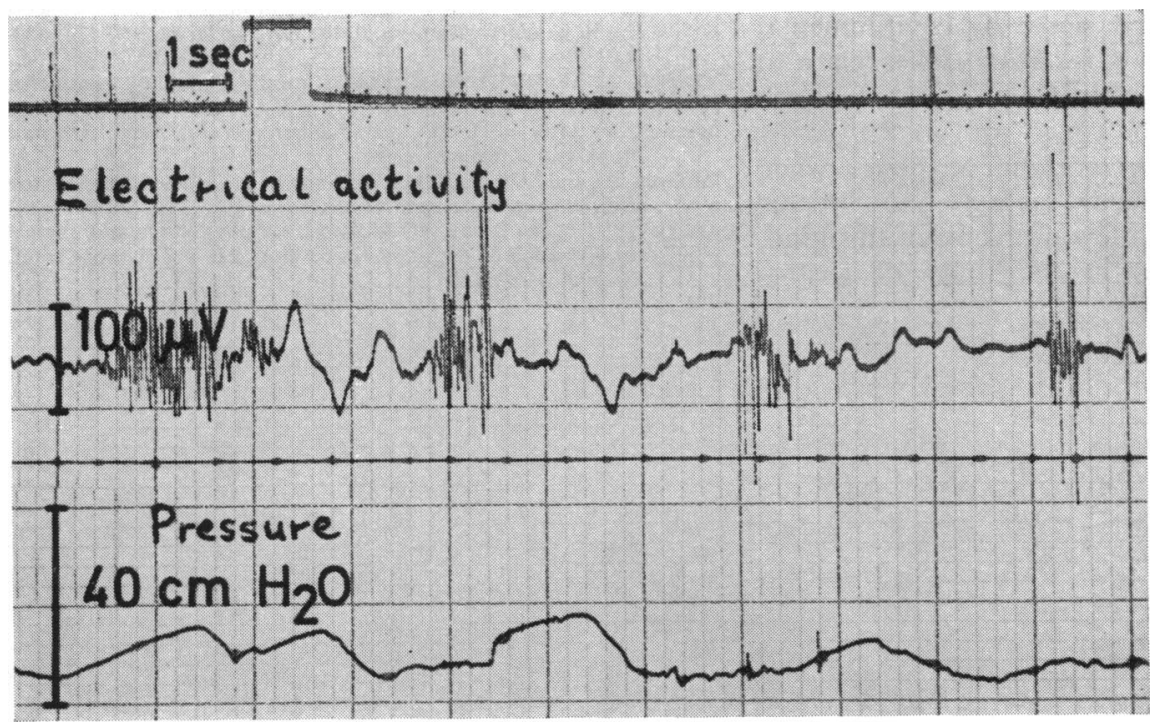

Fig. 4 Recording from third part of duodenum. Electrical time constant 0.06 seconds. Bursts of fast spike potentials accompanied on manometric tracing by pressure waves. 


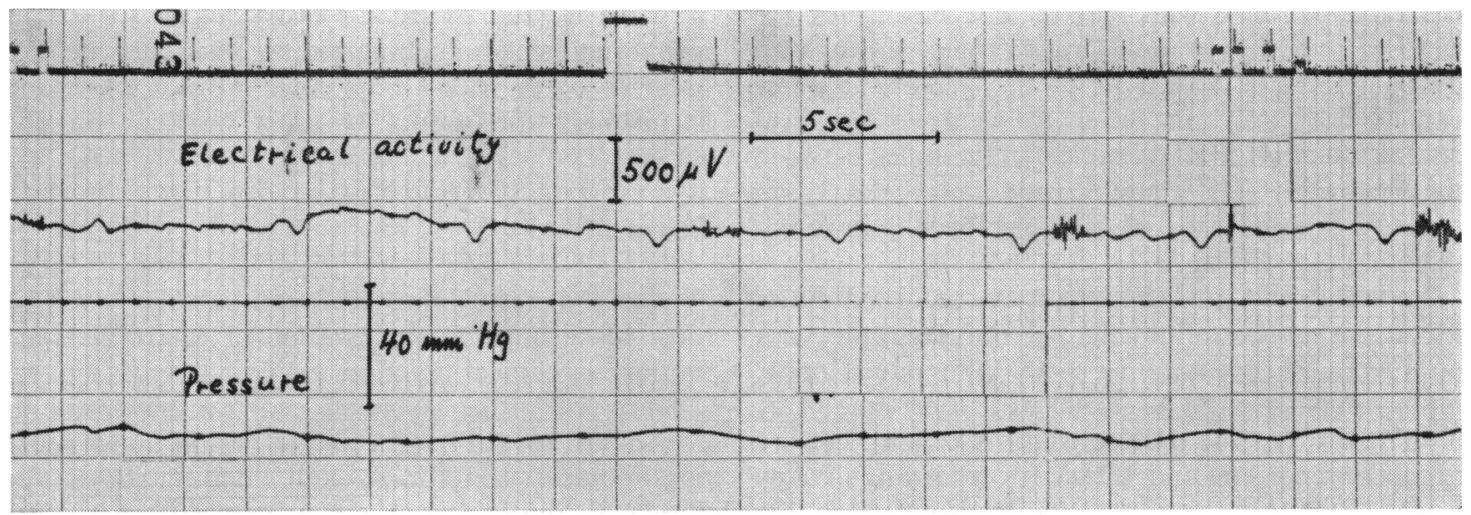

Fig. 5 Recording from third part of duodenum. Electrical time constant: 1.2 seconds. Basic electrical activity seen as negative deflections appearing regularly with a frequency of about 11 per minute. Some of the slow potentials are followed by fast spike potentials.

electrode in the intestinal fluid may act as a stabilizing factor (Atlung, 1972). We have noted that the probe has to remain in position for some minutes (10-15 minutes) until stable recording conditions have been established. The pressure catheter traverses the plastic core with the electrodes and opens at the distal end of the probe (Fig. 2).

For studies in the stomach (antral region) (Fig. 3) a close mucosal contact seems to be essential, and some manipulation is often required in order to establish effective suction because the probe is free to move around in the cavity. When the tip is in the duodenum, on the other hand, the probe is kept in position by the flexures and contact with the bowel wall is easily maintained in most cases even without suction.

Blurring of the electric signal by environmental noise is liable to occur if recording takes place in rooms that are not sufficiently shielded. Such problems will have to be coped with as they arise, (grounding the patient, working at hours when there is little environmental activity, etc). In this department we have had few problems of this kind.

For further progress in the study of gastro- intestinal motility in human subjects, much more clinical experience is needed. Recording of intraluminal pressure and electrical potentials, if possible in combination with synchronized cinefluorography of bowel movements, seems to be a useful approach. Technical difficulties have yet to be overcome. A disposable probe for transnasal intubation may represent a step forward towards a more simplified technique.

The probe is commercially available through Univel A/S, PO Box 42, 2850 Vedbaek, Denmark.

\section{References}

Atlung, S. (1972). Personal communication.

Christensen, J., Schedl, H. P., and Clifton, J. A. (1964). The basic electrical rhythm of the duodenum in normal human subjects and in parients with thyroid disease. J. clin. Invest., 43, 1659 . 1667.

Connell, A. M. (1967). Recording of intestinal motility: routine or research? Gut, 8, 527-529.

Drewes, V. M. (1971). The Small Intestine in Diabetes Mellitus. Munksgaard, Copenhagen.

Monges, H., and Salducci, J. (1970). A method of recording the gastric electrical activity in man. Amer.J. dig. Dis., 15, 271-276.

Quigley, J. P., and Brody, D. A. (1952). A physiologic and clinical consideration of the pressures developed in the digestive tract. Amer. J. Med., 13, 73-81. 